Full Paper

\title{
Radial Combustion Propagation in Iron(III) Oxide/Aluminum Thermite Mixtures
}

\section{Luísa Durães*}

Department of Chemical Engineering, Faculty of Sciences and Technology, University of Coimbra, Pólo II, Pinhal de Marrocos, 3030-290 Coimbra (Portugal)

Laboratory of Energetics and Detonics, Av. da Universidade de Coimbra, 3150-277 Condeixa-a-Nova (Portugal)

\section{José Campos}

Department of Mechanical Engineering, Faculty of Sciences and Technology, University of Coimbra, Pólo II, Pinhal de Marrocos, 3030-201 Coimbra (Portugal)

Laboratory of Energetics and Detonics, Av. da Universidade de Coimbra, 3150-277 Condeixa-a-Nova (Portugal)

\begin{abstract}
António Portugal
Department of Chemical Engineering, Faculty of Sciences and Technology, University of Coimbra, Pólo II, Pinhal de Marrocos, 3030-290 Coimbra (Portugal)
\end{abstract}

DOI: $10.1002 /$ prep.200600006

\begin{abstract}
The self-sustained thermite reaction between iron oxide $\left(\mathrm{Fe}_{2} \mathrm{O}_{3}\right)$ and aluminum is a classical source of energy. In this work the radial combustion propagation on thin circular samples of stoichiometric and over aluminized $\mathrm{Fe}_{2} \mathrm{O}_{3} / \mathrm{Al}$ thermite mixtures is studied. The radial geometry allows an easy detection of sample heterogeneities and the observation of the combustion behavior in their vicinity. The influence of factors like reactant mixtures stoichiometry, samples green density and system geometry on the rate of propagation of the combustion front is analyzed. The radial combustion front profiles are registered by digital videocrono-photography. Combustion thermograms are obtained for two sample radii. Theoretical calculations, based on the impurity levels reported by the reactants manufacturers and on the thermite reaction stoichiometry, were used to define the stoichiometric mixture with unitary equivalence ratio (E. R.). However, it was found from the experimental results that the excess of aluminum only starts for E. R. values between 1.12 and 1.27. This was explained by the further oxidation of aluminum during storage and/or by the reaction incompleteness. In the range studied, the combustion rates of the thermite mixtures did not show any significant dependence on the green density. Combustion rates obtained in this work were slightly higher than those obtained in an earlier work for long square channel geometry. A considerable dispersion of temperature values was observed and attributed to thermocouples sensitivity to micro-scale variations.
\end{abstract}

Keywords: Combustion, Self-Propagating High-Temperature Reaction, Thermite, Iron Oxide, Aluminothermic Reduction

* Corresponding author; e-mail: luisa@eq.uc.pt

\section{Introduction}

The self-propagating high temperature reactions involving a metal and a metal oxide - thermite, two metals - intermetallic, or a metal and a gaseous oxidant-metal oxidation, assume combustion characteristics and are known sources of high energy. Many compositions are proposed in the bibliography [1-3]. These processes are by nature very exothermic, generating extremely high temperatures of reactants and products in the reaction zone (high enough to promote fusion and probable gasification of reactants and products) and enabling self sustainability and propagation of the combustion front. In the self-propagation regime, the combustion front moves fast, but the stability and velocity depend on reactants particle size and shape, reactant mixtures stoichiometry, quality and green density, system geometry, ignition energy, heat generated by the reaction and heating and cooling rates [2].

In this work, the classical thermite reaction between $\mathrm{Fe}_{2} \mathrm{O}_{3}$ and aluminum is studied. Its difficult ignition allows insensitivity levels higher than those observed on other energetic materials. The combustion front propagation rates for this reactive system are commonly low when compared with other pyrotechnic systems. However, the above mentioned parameters influence them considerably. This can be realized examining the published work. Merzhanov and Sytschev [4] reported the first experimental study of gasless combustion, which shows the influence of ambient pressure (from $0.1 \mathrm{MPa}$ to $10 \mathrm{MPa}$ ) and particle size of $\mathrm{Al}(0.3 \mu \mathrm{m}$ 
and $9 \mu \mathrm{m}$ ) on the burning velocity of the $\mathrm{Fe}_{2} \mathrm{O}_{3}+2 \mathrm{Al}+$ $0.9 \mathrm{Al}_{2} \mathrm{O}_{3}$ system with cylindrical geometry. None of the two parameters were found to have a significant effect on the measured velocity. The reported average burning velocity was $0.4 \mathrm{~cm} \cdot \mathrm{s}^{-1}$. Sanin et al. [5] presented results of the combustion rate for different widths of a square long channel confinement. They also studied the addition of alumina as inert additive and the combustion extinction limit of these samples ( $\geq 20 \%$ alumina). In the absence of the inert additive, the combustion rate was $10 \mathrm{~cm} \cdot \mathrm{s}^{-1}$, for a channel $>20 \mathrm{~mm}$ width. For lower widths, lower combustion rates were obtained, $2 \mathrm{~mm}$ being the measured critical channel width. Frolov [6] refers to the $\mathrm{Fe}_{2} \mathrm{O}_{3} / \mathrm{Al}$ system as a pseudo-gasless heterogeneous condensed system, due to the fact that "initial substances and end products are solid but intermediate products may be volatile". The aluminum sub-oxides are volatile and responsible for the dependence of combustion rate on the pressure. He obtained combustion rates from $0.9 \mathrm{~cm} \cdot \mathrm{s}^{-1}$, for atmospheric pressure, to $\approx 4 \mathrm{~cm} \cdot \mathrm{s}^{-1}$, for pressure above 4 MPa. Dilution with alumina was found to reduce combustion temperature and the amount of intermediate products. Kallio et al. [7] reported combustion rates of $2-4 \mathrm{~cm} \cdot \mathrm{s}^{-1}$ for the aluminothermic reduction of a $\mathrm{Fe}_{2} \mathrm{O}_{3} / \mathrm{Fe}_{3} \mathrm{O}_{4}$ mixture in the treatment of steel industry by-products. In this case, there was a considerable amount $(\approx 7-14 \mathrm{wt} \%)$ of other oxides in the effluent under study, acting as diluting agents. Recently, Plantier et al. [8] investigated the influence of stoichiometry in the combustion rate of $\mathrm{Fe}_{2} \mathrm{O}_{3} / \mathrm{Al}$ mixtures for nanometric reactants. They used a long square channel and performed open and confined burning experiments with very low densities (5-8\%TMD). The oxidizers used were either commercially available or obtained by a sol-gel technique. They found that measured combustion rates depended strongly on the oxidizer synthesis technique, the stoichiometry and the confinement conditions. A wide variation of results was obtained with combustion rates varying from a few centimeters to hundreds of meters per second. The annealing pre-treatment of the iron oxide gel increased significantly the combustion rates. In the best set of conditions, values above $900 \mathrm{~m} \cdot \mathrm{s}^{-1}$ were attained.

This study investigates the radial combustion front propagation on thin circular samples of stoichiometric and over aluminized $\mathrm{Fe}_{2} \mathrm{O}_{3} / \mathrm{Al}$ compositions. The radial geom- etry allows the straightforward detection of sample heterogeneities and permits the observation of their effect on the combustion process. The results are compared with theoretical predictions, with experimental results obtained earlier in axial geometry [9], and with literature results. The influence of reactant mixtures composition and green density and system geometry is discussed.

\section{Experimental}

\subsection{Reactants Characterization}

In Table 1 some physical properties of the reactants are presented. Unless otherwise stated, the uncertainties in this Table and in the remaining work are calculated for a $95 \%$ confidence level. The particle sizes, densities, and surface areas were measured by Laser Diffraction Spectrometry (Coulter LS 130), Helium Pycnometry (Mycromeritics Accupyc 1330), and Nitrogen Gas Adsorption (Mycromeritics ASAP 2000), respectively. The average pore diameter was estimated using Nitrogen Gas Adsorption (Mycromeritics ASAP 2000), being only indicative values. Purity data was obtained from manufacturers datasheets. Mössbauer Spectroscopy studies revealed Hematite $\left(\alpha-\mathrm{Fe}_{2} \mathrm{O}_{3}\right)$ as the only phase present in $\mathrm{Fe}_{2} \mathrm{O}_{3}$ Bayferrox 180. An aluminum often used in pyrotechnic applications was chosen. It was dark grey and coated for protection during storage. The aluminum melting point was measured as $\approx 670^{\circ} \mathrm{C}$ by Simultaneous Thermal Analysis (Rheometrics STA 1500), $10^{\circ} \mathrm{C}$ above the pure aluminum value. The difference may be explained by the surface partial oxidation during storage.

\subsection{Mixtures Composition}

The composition of five thermite mixtures is presented in Table 2. T100 is the stoichiometric $\mathrm{Fe}_{2} \mathrm{O}_{3} / \mathrm{Al}$ mixture, being the others over aluminized. E. R.'s are calculated by the molar ratio between "oxygen necessary for the oxidation of the existing $\mathrm{Al}$ to $\mathrm{Al}_{2} \mathrm{O}_{3}$ " and "oxygen actually present in the $\mathrm{Fe}_{2} \mathrm{O}_{3}$ of the mixture". The first term corresponds to the oxygen necessary to meet the stoichiometric condition, i.e. according to the reaction scheme:

Table 1. Physical properties of reactants.

\begin{tabular}{|c|c|c|c|c|c|}
\hline Reactants & $\begin{array}{l}\text { Particle size, } d_{\text {mean }} ; d_{50} \\
\text { and } d_{90}-d_{10}(\mu \mathrm{m})\end{array}$ & Density, $\rho\left(\mathrm{kg} \cdot \mathrm{m}^{-3}\right)$ & $\begin{array}{l}\text { BET surf. area, } \\
A_{\mathrm{s}}\left(\mathrm{m}^{2} \cdot \mathrm{kg}^{-1}\right)\end{array}$ & $\begin{array}{l}\text { Aver. pore diam., } \\
\text { BET; BJH desorp. (nm) }\end{array}$ & Purity (wt\%) \\
\hline $\begin{array}{l}\mathrm{Fe}_{2} \mathrm{O}_{3} \text { Bayferrox } 180 \\
\text { (Bayer) }\end{array}$ & $\begin{array}{l}2.007 \pm 0.081 \\
1.632 \pm 0.045 \\
3.424 \pm 0.186- \\
0.903 \pm 0.019\end{array}$ & $5062.3 \pm 10.7$ & $3149.7 \pm 38.7^{(\mathrm{a})}$ & $14.8 ; 12.6$ & $96-97$ \\
\hline $\begin{array}{l}\text { Al black } 000 \text { india } \\
\text { (Carob) }\end{array}$ & $\begin{array}{l}18.56 \pm 0.62 \\
11.82 \pm 0.32 \\
47.70 \pm 1.62- \\
1.593 \pm 0.103\end{array}$ & $2700.0 \pm 7.1$ & $4475.2 \pm 29.9^{(a)}$ & $23.8 ; 19.0$ & 89.3 \\
\hline
\end{tabular}

(a) In this case, the uncertainty of the mean value is defined by the standard deviation. 
Table 2. Composition of thermite mixtures.

\begin{tabular}{|c|c|c|c|c|c|}
\hline Mixtures & $\begin{array}{l}\mathrm{Fe}_{2} \mathrm{O}_{3} \text { Bayferrox } 180 \\
\text { (Bayer) } \\
\text { Purity }=96 \% \\
(\mathrm{wt} \%)\end{array}$ & $\begin{array}{l}\text { Al black } 000 \text { india } \\
(\text { Carob) } \\
\text { Purity }=89.3 \% \\
(w t \%)\end{array}$ & $\begin{array}{l}\mathrm{Fe}_{2} \mathrm{O}_{3} / \mathrm{Al} \text { relative } \\
\text { compositions } \\
(\mathrm{wt} \%)\end{array}$ & $\begin{array}{l}\text { Equivalence } \\
\text { ratio }\end{array}$ & $\begin{array}{l}\text { Theoretical Maximum } \\
\text { Density (TMD) } \\
\left(\mathrm{kg} \cdot \mathrm{m}^{-3}\right)\end{array}$ \\
\hline $\mathrm{T} 100$ & 73.35 & 26.65 & $74.74 / 25.26$ & 1.00 & 4105 \\
\hline $\mathrm{T} 112$ & 71.03 & 28.97 & $72.50 / 27.50$ & 1.12 & 4039 \\
\hline T127 & 68.46 & 31.54 & $70.00 / 30.00$ & 1.27 & 3967 \\
\hline $\mathrm{T} 142$ & 65.89 & 34.11 & $67.50 / 32.50$ & 1.42 & 3899 \\
\hline T159 & 63.34 & 36.66 & $65.00 / 35.00$ & 1.59 & 3833 \\
\hline
\end{tabular}

$\mathrm{Fe}_{2} \mathrm{O}_{3}+\mathrm{Al} \rightarrow 2 \mathrm{Fe}+\mathrm{Al}_{2} \mathrm{O}_{3} \quad\left(\Delta_{\mathrm{f}, 298 \mathrm{~K}} H^{\mathrm{o}}=-850 \mathrm{~kJ} \cdot \mathrm{mol}^{-1}\right)$

Impurities are considered in the above calculation.

After weighting and adding individual reactants, each mixture was homogenized in a rotary mixer during 24 hours. Caked material was scrapped by using an industrial mixer, at low speed, during thirty minutes. The good quality of the mixtures was confirmed by optical microscopy (microscope Nikon Optiphot HFX-II).

\subsection{Experimental Set-Up}

Prior to the combustion process, reactant mixtures were pressed, in a stainless steel circular box with an inner PMMA lid (cf. Figure 1), by a cold uniaxial press (hydraulic press COMPAC P60), at $200 \mathrm{MPa}$ for five minutes. The pressing process was repeated once, if the compaction level attained in the first pressing was low. Samples of 1-2 mm thickness were obtained and the compaction levels varied from 50 to $70 \%$ TMD (calculated by weight and geometry measurements).

A schematic diagram of the experimental set-up used in the combustion experiments is given in Figure 2. The selfpropagating reaction was initiated, in an uncompressed mixture filling the ignition channel, via a nichrome resistive wire, instantaneously heated by means of a $100 \mathrm{~V}$ capacitor discharge. The radial combustion rates were estimated via digital video-crono-photography. Time resolution was 50 frame $\cdot \mathrm{s}^{-1}$ and shutter speed $250 \mu \mathrm{s}$. Video frames, taken every $0.04 \mathrm{~s}$, allowed the definition of combustion front propagation profiles for each experiment. Figure 3 shows a sequence of video frames of the radial combustion front propagation for a T159 experiment. Combustion thermograms were obtained at two different radii $(10 \mathrm{~mm}$ and $20 \mathrm{~mm}$ from the centre), using Tungsten/Rhenium thermo- couples (Omega, type C), connected to an amplifier and to a fast digital signal analyzer. Figure 4 shows a typical record of thermocouples signals. Calibration curves of amplifier and thermocouples allow the calculation of temperature values from the registered voltage.

\section{Results and Discussion}

The video frames have shown approximately circular radial combustion profiles and improved regularity and definition was obtained for high values of the radius. This fact corroborates the good quality of mixing, already observed by optical microscopy. Hot spots were detected during propagation, with notorious high light emission (cf. Figure 3). Figure 5 shows selected scans of after burning products for the five mixtures under study. The products remained in islands due to coalescence and crystallization at preferential points. The agglomeration of products was more significant in mixtures with lower aluminum content. In this case, the combustion rates were lower and less spreading of products occurred. Figure 6 shows typical combustion front propagation profiles and corresponding radial combustion rate for T100, T127, and T159 mixtures. Results for T112 and T142 mixtures are omitted for simplicity. Combustion performance of T112 is marginally better than T100. T142 has a combustion performance in between T127 and T159. The radial position of the front versus time is approximately linear, resulting in quasistationary radial combustion rates (cf. Figure 6). The dispersion of radial combustion rate values versus radius is mainly due to the numerical approximation of the derivative calculation. The dispersion is higher near the origin-from $\mathrm{r}=0$ to $\mathrm{r} \approx 0.005 \mathrm{~m}$-due to lower accuracy in the position variable and to the transient behavior of combustion onset. Based on the combustion profiles between $\mathrm{r}=0 \mathrm{~m}$ and $\mathrm{r}=$

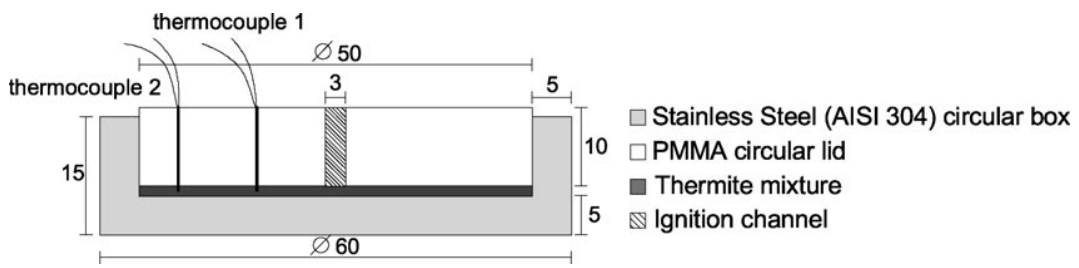

Figure 1. Experimental sample set-up (front view cut). All dimensions in millimeters. 


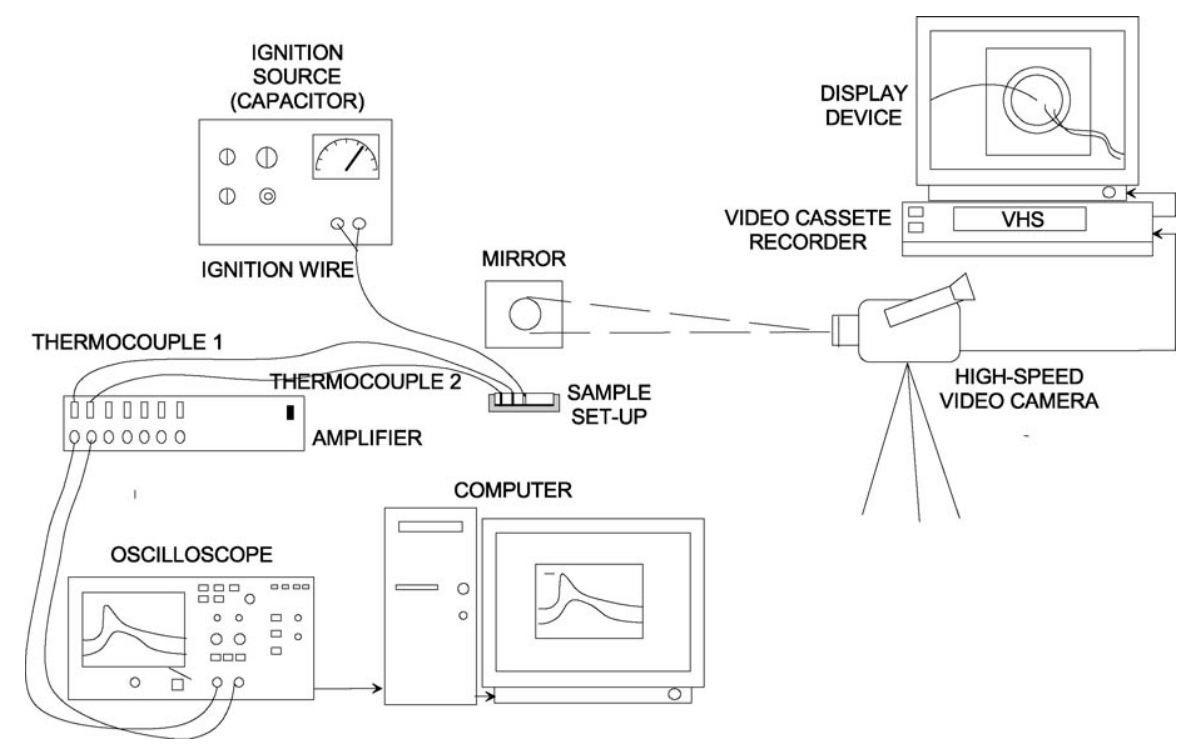

Figure 2. Experimental set-up used in the combustion experiments.

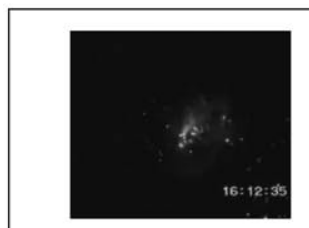

$0.04 \mathrm{~s}$

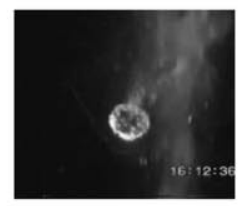

$0.28 \mathrm{~s}$

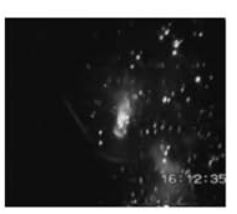

$0.08 \mathrm{~s}$

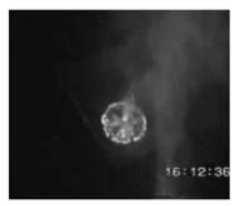

$0.32 \mathrm{~s}$



$0.12 \mathrm{~s}$

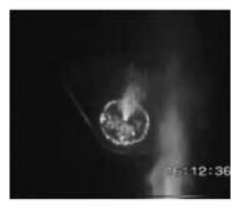

$0.36 \mathrm{~s}$

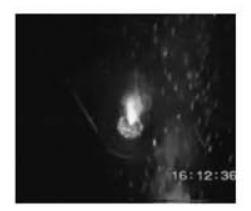

$0.16 \mathrm{~s}$

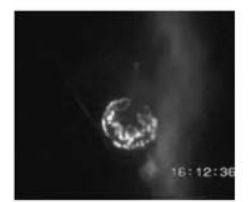

$0.40 \mathrm{~s}$

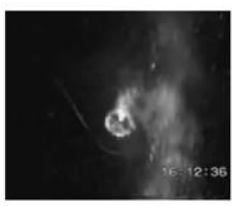

$0.20 \mathrm{~s}$

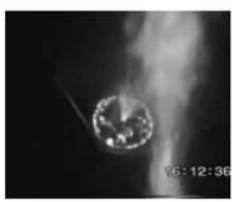

$0.44 \mathrm{~s}$

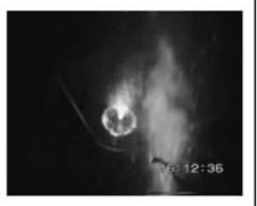

$0.24 \mathrm{~s}$

Figure 3. Example of the radial combustion front propagation for T159 mixture. On the right bottom are shown the corresponding combustion front propagation profiles (the external profile is the circular box confinement; $T$ indicates the direction where the thermocouples were positioned).

$0.025 \mathrm{~m}$ and between $\mathrm{r}=0.005 \mathrm{~m}$ and $\mathrm{r}=0.025 \mathrm{~m}$, Figure 7 presents the combustion rates for each experiment. The combustion rates along the $10 \mathrm{~mm}$ linear distance of the thermocouples radius path can also be calculated, considering the time gap between the two signals (cf. Figures 4 and 7). A previous examination of results based on physical and statistical arguments led to the rejection of some outliers (not included in the figure). The mean combustion rates are displayed by lines in Figure 7. Results show an increase of mean combustion rates with increasing aluminum content in the mixtures.

As expected, the mean combustion rates calculated including the initial points of the combustion profiles are higher than those obtained without these points. The values obtained from combustion profiles for radii between $0.005 \mathrm{~m}$ and $0.025 \mathrm{~m}$ are better estimates of the combustion rates in the quasi-stationary regime of propagation. The first increment in combustion rate, from T100 to T112, is smooth and can be ascribed to over-estimated purity level of

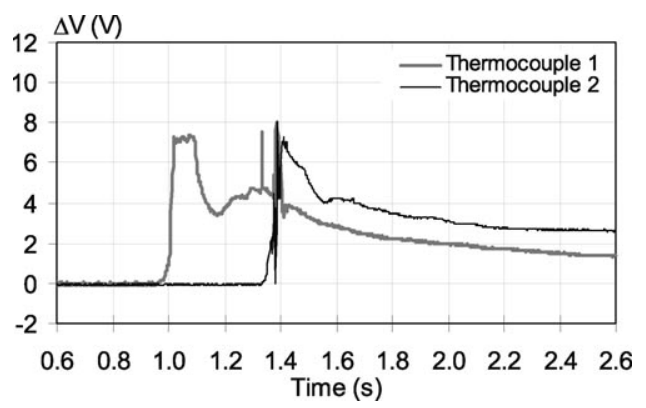

Figure 4. Typical experimental record of thermocouples signals. Example of a T100 combustion experiment. 




(a)

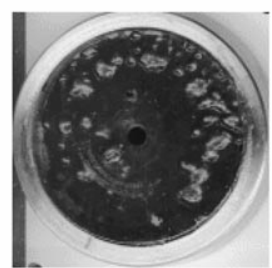

(b)

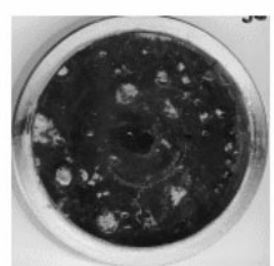

(c)

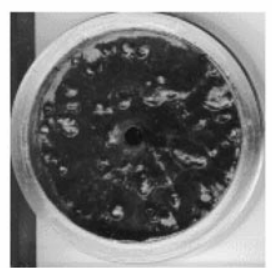

(d)

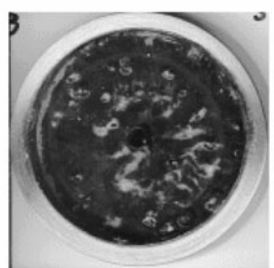

(e)

Figure 5. Selected scans of after burning products for (a) T100, (b) T112, (c) T127, (d) T142, and (e) T159 mixtures.

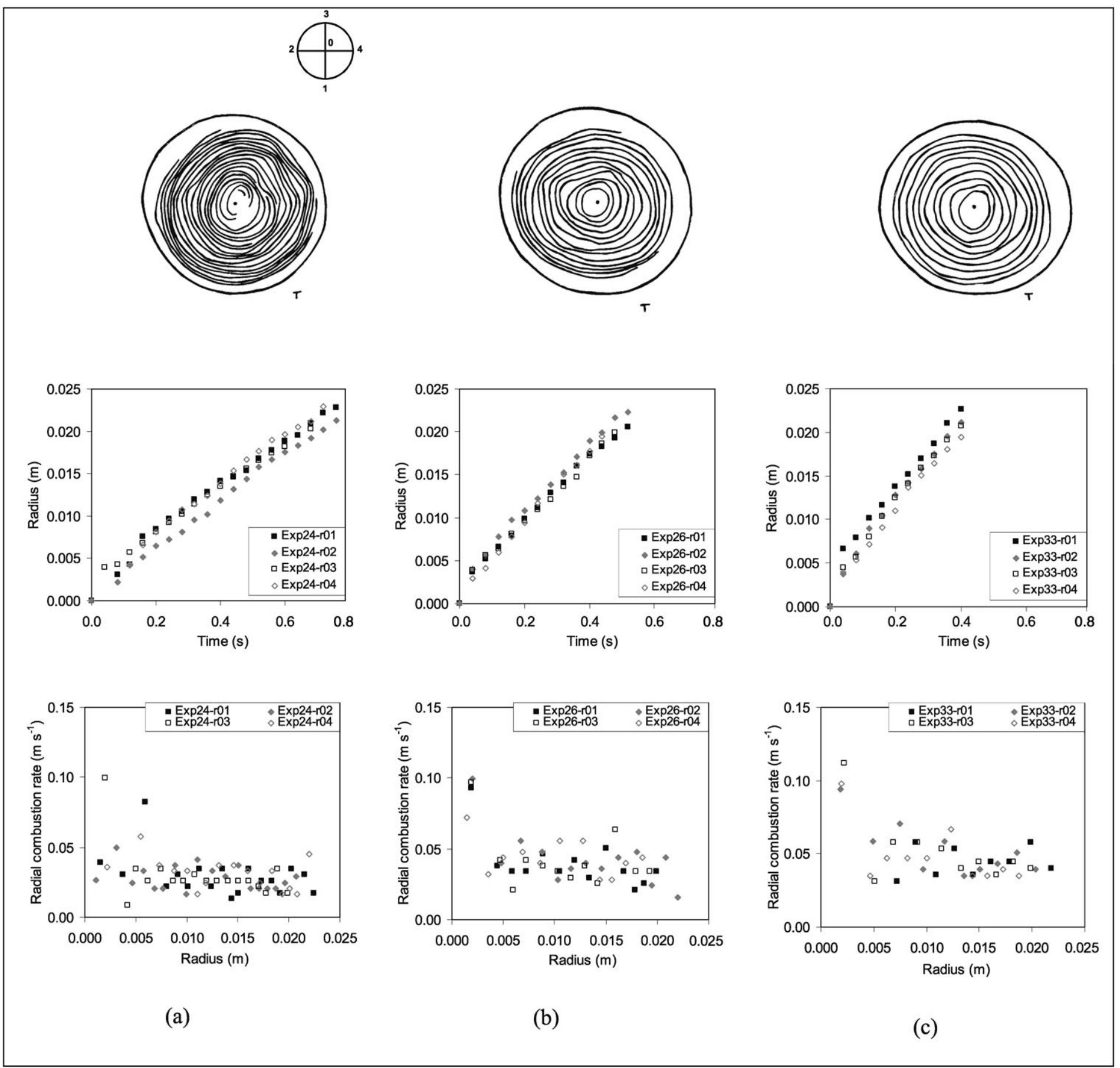

Figure 6. Typical profiles and corresponding radial combustion rates for (a) T100, (b) T127, and (c) T159. 




Figure 7. Calculated radial combustion rates (a) via thermocouples signals, (b) with film profiles between $\mathrm{r}=0 \mathrm{~m}$ and $\mathrm{r}=0.025 \mathrm{~m}$ and (c) with film profiles between $\mathrm{r}=0.005 \mathrm{~m}$ and $\mathrm{r}=0.025 \mathrm{~m}$ (for (b) and (c), each point corresponds to the mean value of the four paths considered in Figure 6). The behaviors of mean combustion rates are given by lines in each case.

aluminum due to oxidation during storage (in spite of the aluminum coating) and/or mass and energy dispersion in sub-products due to incomplete reaction (more significant in regions where the heat losses to the surroundings were significant). Thermite reaction mechanism via iron aluminates and the crystallization extent of alumina and iron from these intermediate compounds depend on the $\mathrm{Fe}_{2} \mathrm{O}_{3} / \mathrm{Al}$ relative proportion and on the combustion temperature achieved; the maximum combustion temperature and rate are expected when full conversion of intermediate compounds takes place. This means that experimental stoichiometry of $\mathrm{Fe}_{2} \mathrm{O}_{3} / \mathrm{Al}$ mixtures, in the sense of complete reaction to alumina and iron products, is not located on E. R. =1 (T100). Instead, it may occur for E. R. values between 1.12 and 1.27, where the increment in combustion rate is particularly pronounced. X-ray diffraction measurements and Mössbauer spectroscopy of the combustion products are currently underway and preliminary results indicate the formation of $\mathrm{Fe}_{3} \mathrm{Al}$ from $\mathrm{T} 127$ to $\mathrm{T} 159$ mixture. This fact corroborates the excess of $\mathrm{Al}$ (E. R. > 1) from 1.27 to higher E. R. values. Thus, the sudden increase observed between T112 and T127 mixture and further behavior may be explained by a consecutive exothermic reaction taking place, involving aluminum excess and Fe product formed by the thermite reaction, according to (2).
$3 \mathrm{Fe}+\mathrm{Al} \rightarrow \mathrm{Fe}_{3} \mathrm{Al} \quad\left(\Delta_{\mathrm{f}, 298 \mathrm{~K}} H^{\mathrm{o}}=-66.9 \mathrm{~kJ} \cdot \mathrm{mol}^{-1}\right)$

The slightly exothermic character of this reaction enhances the combustion propagation rate of the thermite reaction.

The behavior of the mean points based on the thermocouples signals is different from the mentioned above at E. R. around 1.27. This can be explained by the calculation of the mean with fewer points than in the previous cases. Table 3 presents all the results and corresponding uncertainties. The ignition delay times in Table 3 support the conclusion of the higher exothermic nature of T127 to T159 mixtures combustion when compared to T100 and T112. There is a sharp reduction of the ignition delay time from T100 to T127, being less accentuated thereafter. Chow and Mohler [12] studied the ignition time of $\mathrm{Fe}_{2} \mathrm{O}_{3} / \mathrm{Al}$ stoichiometric mixtures as a function of laser power and reactants particle size. They reported ignition times in the range of $0.15-1 \mathrm{~s}$, in agreement with the results of this work.

In a few experiments, some irregularities in combustion propagation profiles are observable (cf. Figure 8). In (a), a preferential combustion of one hemisphere of the sample, followed by the combustion of the other, may be the consequence of an asymmetrical ignition and/or sample thickness variations. In (b), the combustion in one hemisphere of the sample seems to extinguish or to be less intense (invisible with the optical filter), probably due to the very low thickness of this sample, particularly in this hemisphere $(\approx 1 \mathrm{~mm})$. In $(\mathrm{c})$, the combustion rate was three times higher than the mean value for this mixture. The shadowed region corresponds to very high light emission observed in the second film frame (as the video camera was dimmed, the corresponding profile is not shown in the figure). This faster combustion behavior can be explained by a preferential burning path occurring between the PMMA lid and the sample, leading to a multi-point initiation in that region. Glue was used to fill the PMMA/sample interface, to avoid this phenomenon. (d) presents a significant, but exceptional, thermocouples interference in the combustion propagation.

The obtained results are in agreement, i.e. in the same order of magnitude, with results of Sanin et al. [5], Frolov [6], and Kallio et al. [7] (cf. Section 1). Considering the experimental conditions used by these authors, it can be concluded that pressure conditions, samples green density, and system geometry did not lead to changes in the combustion rate order of magnitude. On the contrary,

Table 3. Mean ignition delays and mean combustion rates for the studied thermite mixtures.

\begin{tabular}{|c|c|c|c|c|}
\hline Mixture & $\begin{array}{l}\text { Mean ignition } \\
\text { delay }(\mathrm{s})\end{array}$ & $\begin{array}{l}\text { Mean combustion rate obtained } \\
\text { via thermocouples signals \{radius } \\
\in[0.01,0.02 \mathrm{~m}]\}\left(\mathrm{m} \cdot \mathrm{s}^{-1}\right)\end{array}$ & $\begin{array}{l}\text { Mean combustion rate obtained } \\
\text { by video profiles }\{\text { radius } \\
\in[0,0.025 \mathrm{~m}]\}\left(\mathrm{m} \cdot \mathrm{s}^{-1}\right)\end{array}$ & $\begin{array}{l}\text { Mean combustion } \\
\text { rate obtained by video } \\
\text { profiles }\{\text { radius } \\
\in[0.005,0.025 \mathrm{~m}]\}\left(\mathrm{m} \cdot \mathrm{s}^{-1}\right)\end{array}$ \\
\hline T100 & $0.89 \pm 0.13$ & $0.029 \pm 0.008$ & $0.0300 \pm 0.0033$ & $0.0269 \pm 0.0022$ \\
\hline T112 & $0.66 \pm 0.12$ & $0.031 \pm 0.011$ & $0.0324 \pm 0.0022$ & $0.0299 \pm 0.0038$ \\
\hline T127 & $0.38 \pm 0.04$ & $0.038 \pm 0.012$ & $0.0416 \pm 0.0055$ & $0.0376 \pm 0.0067$ \\
\hline T142 & $0.32 \pm 0.06$ & $0.047 \pm 0.008$ & $0.0457 \pm 0.0026$ & $0.0413 \pm 0.0034$ \\
\hline T159 & $0.24 \pm 0.06$ & $0.050 \pm 0.006$ & $0.0509 \pm 0.0023$ & $0.0474 \pm 0.0022$ \\
\hline
\end{tabular}




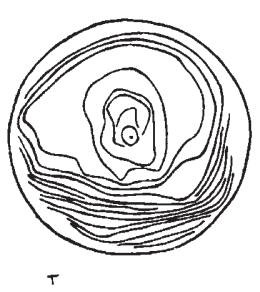

(a)

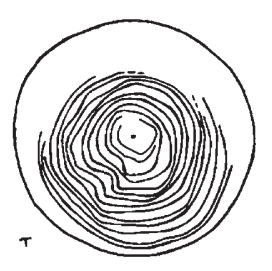

(b)

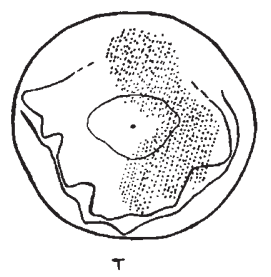

(c)

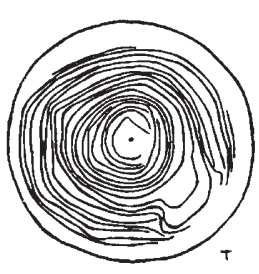

(d)

Figure 8. Selected cases of strong irregularities in the combustion front propagation. Description of cases (a) - (d) are in the text.

reactants particle size, mixtures stoichiometry, dilution and confinement are factors with significant effects. In earlier work [9], a long square PMMA channel $(175 \times 5 \times 5 \mathrm{~mm})$ was filled with T100 and T127 thermite mixtures, to study the combustion rates in self-propagating and field-assisted (by continuous electrical discharge) modes. Green densities were low, ranging from 25 to $33 \%$ TMD. A set of three optical fibres, coupled to a photodiode system and connected to a fast digital signal analyzer, were used to evaluate average combustion rates. In the self-propagating mode, the obtained values were $1.5 \mathrm{~cm} \cdot \mathrm{s}^{-1}$ and $2.5 \mathrm{~cm} \cdot \mathrm{s}^{-1}$ for T100 and T127 mixtures, respectively. In this work, for the same two mixtures, the combustion rates were slightly higher.

Figure 9 shows a weak positive correlation between samples green density and E. R. Aluminum seems to act like a binder and lubricant for the iron oxide particles in the press process. However, the measured combustion rates, for each thermite mixture, do not show a significant dependence on corresponding densities, in the studied range (cf. Figure 10). This dependence may have been masked by the variation of combustion rate data.

In Figure 11, the experimental temperature measurements for different compositions are shown. For the experimental set-up, it was decided not to use insulation of the hot junction of the thermocouples for improved sensitivity of the temperature measurement. The price paid was a significant variation of the temperature results due to micro-scale variations, i.e, local changes of thermocouples environment in their position in the sample. Therefore, depth of thermocouple insert in the sample and amount and type of combustion products glued to the hot junction at

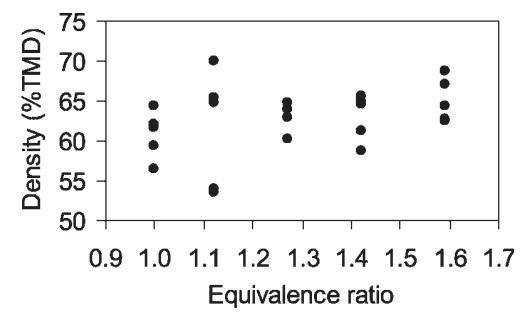

Figure 9. Thermite samples green density as a function of its equivalence ratio.

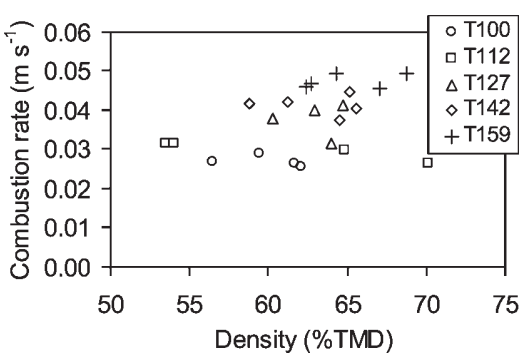

Figure 10. Calculated radial combustion rates with film profiles between $\mathrm{r}=0.005 \mathrm{~m}$ and $\mathrm{r}=0.025 \mathrm{~m}$, as a function of thermite samples green density.

the time the wave passes, are two factors that affect the temperature signal. This last factor is anticipated due to the insulator nature of alumina, one of the reaction products. Another phenomenon liable to affect the measurement is the electromotive force dissipation through the stainless steel box that confines the sample. Short time interferences on the thermocouples signals after the onset of the second thermocouple signal were detected in some experiments. Since there is an experimental evidence of Fe melting during the reaction, all temperature values below $1300^{\circ} \mathrm{C}$ were eliminated $\left(\approx 250^{\circ} \mathrm{C}\right.$ below the melting temperature of $\left.\mathrm{Fe}\right)$.

Although a significant variation of local temperatures occurred, the calculated mean temperatures for thermocouple 1 and 2 are similar for each composition (cf.

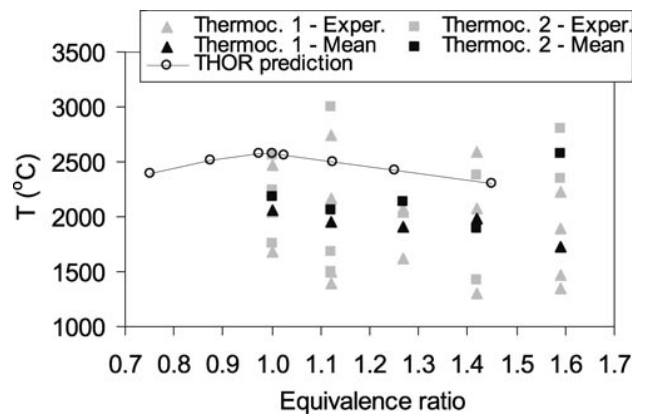

Figure 11. Combustion front temperatures and means at two sample radii in the same path $(\mathrm{r}=0.01 \mathrm{~m}$ and $\mathrm{r}=0.02 \mathrm{~m})$. Comparison with THOR code results. 
Figure 11). This gives a clear indication that the combustion regime was stationary and already established by the first thermocouple position. It can also be concluded that the mean reaction temperature is not particularly sensitive to changes in the mixtures composition in the studied range of equivalence ratios. The global combustion of $\mathrm{Fe}_{2} \mathrm{O}_{3} / \mathrm{Al}$ mixtures was simulated using THOR thermochemical code. It allows the prediction of the combustion products composition as a function of their final PVT state [9-11]. THOR code prediction, as expected, gave maximum adiabatic combustion temperature for E. R. $=1$, where mass and energy are less dispersed on sub-products with higher enthalpy of formation than stoichiometric products. In the calculation no heat losses to the surrounding are considered and reaction extent is ignored. Therefore, the calculated values are higher than the experimental values of temperature. The high thermal conductivity of stainless steel, combined with the low sample thicknesses, may cause high heat losses from the experimental system to the surrounding, accentuating this difference. Fisher and Grubelich [1] calculated the adiabatic combustion temperature of the $\mathrm{Fe}_{2} \mathrm{O}_{3} / \mathrm{Al}$ stoichiometric composition, with and without phase changes in the products. They found $2862^{\circ} \mathrm{C}$ and $4109^{\circ} \mathrm{C}$ for each case. THOR predictions are in good agreement with the first value.

\section{Conclusions}

The radial combustion profiles of the studied $\mathrm{Fe}_{2} \mathrm{O}_{3} / \mathrm{Al}$ mixtures were approximately circular. Improved regularity and sharpness was obtained for high values of the radius. The combustion propagation clearly involved the formation of hot-spots. The combustion rate results have shown an increase of the mean combustion front propagation rates with increasing aluminum content in the mixtures. The experimental stoichiometry of $\mathrm{Fe}_{2} \mathrm{O}_{3} / \mathrm{Al}$ mixtures, in the sense of complete reaction to alumina and iron products, was not located at E. R. = 1 (T100). This experimental point was located between the T112 and T127 mixtures, where an excess of aluminum appeared. In the studied range, the measured combustion rates did not show any dependence on density. The combustion rates obtained in this work were slightly higher than those obtained in earlier work for long square channel geometry. This discrepancy can be attributed to samples geometries and/or green densities. Thermocouples high sensitivity led to a significant variation of the temperature results due to micro-scale variations. The calculated mean temperatures were not particularly affected by the samples composition in the range of E. R. studied. THOR code prediction establishes an upper limit to the mean combustion temperatures, since it considers adiabatic conditions and complete reaction. These conditions are not fully met experimentally.

\section{References}

[1] S. H. Fisher, M. C. Grubelich, Theoretical Energy Release of Thermites, Intermetallics and Combustible Metals, 24th International Pyrotechnics Seminar, Monterey, California, USA, 27-31 July 1998, pp. 231.

[2] J. J. Moore, H. J. Feng, Combustion Synthesis of Advanced Materials: Part I. Reaction Parameters, Progress in Materials Science 1995, 39, 243.

[3] J. J. Moore, H. J. Feng, Combustion Synthesis of Advanced Materials: Part II. Classification, Applications and Modelling, Progress in Materials Science 1995, 39, 275.

[4] A. G. Merzhanov, A. E. Sytschev, About Self-Propagating High-Temperature Synthesis, http://www.ism.ac.ru, 2001.

[5] V. N. Sanin, S. L. Silyakov, V. I. Yukhvid, Models of Combustion of Heterogeneous Melting Systems in a Long Channel, International Journal of Self-Propagating High-Temperature Synthesis 1992, 1(2), 191.

[6] Y. V. Frolov, Combustion of Heterogeneous Condensed Systems, 27th International Pyrotechnics Seminar, Grand Junction, Colorado, USA, 16-21 July 2000, pp. 463.

[7] M. Kallio, P. Ruuskanen, J. Mäki, E. Pöyliö, S. Lähteenmäki, Use of Aluminothermic Reaction in the Treatment of Steel Industry By-Products, Journal of Materials Synthesis and Processing 2000, 8(2), 87.

[8] K. B. Plantier, M. L. Pantoya, A. E. Gash, Combustion Wave Speeds of Nanocomposite $\mathrm{Al} / \mathrm{Fe}_{2} \mathrm{O}_{3}$ : the Effects of $\mathrm{Fe}_{2} \mathrm{O}_{3}$ Particle Synthesis Technique, Combust. Flame 2005, 140 (4), 299.

[9] J. Morgado, L. Durães, J. Campos, A. Portugal, Iron Oxide/ Aluminum Fast Thermite Reaction, in M. D. Furnish, Y. M. Gupta, J. Forbes (Eds), Shock Compression of Condensed Matter-2003 - AIP Conference Proceedings Series, The American Institute of Physics, New York 2004, pp. 871.

[10] L. Durães, J. Campos, J. C. Gois, New Equation of State for the Detonation Products of Explosives, in S. C. Schmidt, W. C. Tao (Eds), Shock Compression of Condensed Matter1995, Part. 1 - AIP Conference Proceedings Series, Vol. 370, The American Institute of Physics, Woodbury (NY) 1996, pp. 385.

[11] L. Durães, J. Campos, A. Portugal, Thermodynamical Prediction of Combustion and Detonation Properties Using Modified THOR Code, 27th International Pyrotechnics Seminar, Grand Junction, Colorado, USA, 16-21 July 2000, pp. 55.

[12] C. T. S. Chow, J. H. Mohler, Thermal Ignition of Pyrotechnics with Lasers, 3e Congrès International de Pyrotechnie $d u$ Groupe de Travail de Pyrotechnie Spatiale et 12th International Pyrotechnics Seminar, Juan-les-Pins, 8-12 June 1987, pp. 55.

(Received April 18, 2005; Ms 2005/020) 